\title{
Fashion Sector and Instagram Influencers. The case of Albania.
}

\author{
KRESHNIK BELLO \\ European University of Tirana \\ Rr.”Xhanfize Keko", Nd.56, Tirana, Albania \\ ALBANIA \\ HYSEN MUCEKU \\ European University of Tirana \\ Rr.”Xhanfize Keko", Nd.56, Tirana, Albania \\ ALBANIA \\ MARGARITA NDOKA \\ European University of Tirana \\ Rr."Xhanfize Keko", Nd.56, Tirana, Albania \\ ALBANIA
}

\begin{abstract}
Nowadays we face an ever-growing number of people using social media, and Instagram is one of the most popular, where its users are exposed to the content generated by opinion leaders/influencers. The role of influencers has already been acknowledged by both academy and the companies, yet the literature in regard with this topic faces some limitations. At the same time, evidence shows that Instagram is the mostly used platform by influencers/opinion leaders in the fashion industry and influencers/opinion leaders are an important source of impact for their followers. The aim of this paper is to explore the role that influencers on Instagram play in the behavior of consumers. Its main objective is the identification of the impact that some antecedents (stimuli) have on the opinion leadership, as well as the impact that the latter has on the consequent (response) purchase intention of consumers, in the fashion sector in Albania. The research followed a quantitative approach, with a sample of 412 followers of a fashion focused Instagram account (of a non-traditional celebrity), that answered an online questionnaire. The results of the research suggest that opinion leadership impacts the consumer behavioral intentions. In regard with the practical and theoretical implications, this study contributed to a better understanding of the role of Instagram influencers in fashion sector, allowing the enrichment of literature and information in the Albanian environment. The research has also provided evidence that the use of influencers is a successful tool for marketers and companies in the fashion sector.
\end{abstract}

Key-Words: - Fashion Sector, Instagram, Online Influencer, Impact, Opinion Leadership, Intention to Purchase Received: June 3, 2021. Revised: September 12, 2021. Accepted: October 1, 2021. Published: October 18, 2021.

\section{Introduction}

Nowadays, traditional marketing has already given way to online marketing through social media, as it has invaded our daily lives and can reach a wider audience in a relatively shorter period of time and at a lower cost compared to traditional marketing. The tools and strategies for dealing with customers have changed a lot with the emergence of this phenomenon (social media), also referred to as consumergenerated media [34]. The 21 st century is witnessing an explosion of messages transmitted through these media. They have become a major factor in influencing various aspects of consumer behavior including awareness, information acquisition, opinions, attitudes, purchase behavior, and postpurchase communication and evaluation. This media comprises both the conduits and the content disseminated through interactions between individuals and organizations [25].

The significance of this study lies in the identification of the way influencers become trusted sources for their followers, as well as the way opinion leadership impacts the intention of consumers to purchase the promoted products. Moreover, this study provides guidelines for marketers and companies operating in the fashion sector, with theoretical and practical implications in approaching 
markets via influencer marketing and Instagram influencer initiatives. Social media are still developing, and they offer more and more possibilities to users due to their continuous upgrades [53]. Despite the increasing number of influencers who have emerged in the fashion industry, this is (to our knowledge) one of the first studies analyzing the antecedents and their effect on opinion leadership, as well as one of the most important consequence of the opinion leadership impact on consumer behavior (intention to purchase), on Instagram, in the Albanian context [6].

Social media are defined as the activities, participations, and behaviors of people in online communities to share information, knowledge and opinions [14]. Social media content comprises text, pictures, videos, and networks. Almost all of businesses use social media to market their brands and products, due to their ability to increase brand exposure, attract website traffic, develop loyal fans, and gain marketplace intelligence [40].

At the same time, consumers are increasingly using social media to find out about brands and products [29] and access this media on their mobile devices, allowing marketers more touch-points to reach their consumers. Social media activities for a brand can foster the consumer base of the brand [49], and engagement in social media brand communities increases consumers' purchase expenditures [16]. Millions of companies have set up social media pages for brand communication purposes, and the popularity of social media requires theoretical understanding of how social media exposures influence product-related outcomes [49].

Defined as the identification and use of specific key individuals who hold influence over potential buyers of a brand or product to aid in the marketing activities of the brand [5], influencer marketing can act as a powerful mechanism for impacting. In previous research, use of influencers such as celebrities [11] and bloggers [27], have been found to significantly increase consumers' positive brand attitudes and purchase intentions. However, there also exist issues of the security of social networking users. The dangers that have occasionally been reported to arise from the use of technology and social networks are many and are constantly renewed [55]. However, this issue might be the focus of another study.

Instagram, a photo- and video-sharing mobilebased social media app is currently one of the most popular social media platforms for influencer marketing. Unfortunately, the business publications and academic literature do not offer marketing and other managers much guidance for incorporating social media into their marketing strategies. Therefore, many managers lack a full comprehension of the role of social media in the marketing efforts of the companies, and this is true for Albanian managers either. The research presents the power of influencers who use social media to express their views, and the behavior of consumers that is impacted by their posted content, pictures and videos [53].

In the academic aspect, this paper contributes to the existing literature by providing insight on the relationship between consumer behavior and online influencers, therefore bringing new evidence into the underlying theories. This study allows a better understanding of the perceptions that consumers have about Instagram influencers, which is still an area not broadly investigated [52], especially in the Albanian context.

The authors believe that this study contributes to the existing opinion leadership literature conceptually and empirically. So, a conceptual framework was developed to illustrate the relationships between antecedents of opinion leadership and the intention to purchase of the followers, as well as the effects that some other important (consumer perceived) variables have on this relationship [54]. The authors also believe that this research framework extends and enriches prior studies within the relevant fields. The results of the research also confirm some of the assumptions of the underlying theories [52].

This study has practical implications as well. This study identifies influencers based on the content they publish [6]. So, consumers who follow an influencer who publishes qualitative and useful content may develop behaviors that may benefit both the influencer and companies. Therefore, companies must consider the match between the way consumers live their lives and the kind of content published by influencers when they want to involve them in an marketing campaign [56]. The results of this research also confirm the fact that influencers should be considered in the fashion industry, as many consumers follow them and imitate their views toward the fashion [6]. Finally, given the insufficiency of studies in this area (in the Albanian environment), this study contributes to the marketers who invest more and more in using influencer marketing as part of their strategies [52].

\section{Literature Review}

Theoretical review is based on the following issues:

\subsection{Study supporting theories}


There are four theories that we may indicate as important to the context of this paper: the social identity theory, the theory of planned behavior, the theory of planned reason (reasoned action), and the social learning theory.

Tajfel and Turner's social identity theory explains that part of a person's concept of self comes from the groups to which that person belongs. It suggests that the group we identify with is important to our selfesteem and sense of identity. Reference groups have a diverse impact on purchase intention under different stimuli [22]. Whereas identification with a group is claimed to be based on the desire for selfdefinition, identification with an individual is argued to be predicated on the desire to conciliate, imitate, or vicariously gain the qualities of the other [3]. That could explain the success of online influencers [37].

The theory of reasoned action and the theory of planned behavior provide some conceptual framework for understanding the factors that affect influencer trust and purchase intention. The two closely associated theories suggest that a person's behavior is determined by his/her intention to perform a behavior [37]. A person's intention to perform a behavior is predicted by: 1) a person's attitude toward the behavior, and 2) subjective norms regarding the behavior. Subjective norms are the result of social and environmental surroundings and a person's perceived control over the behavior. Generally, positive attitude and positive subjective norms increase the likelihood of intentions governing changes in behavior. Trust has been regarded as one of the most important reasons which encourages customers to purchase behavior and a high level of trust in influencer causes a positive attitude and a high intention to purchase [37] [30].

The social learning theory posits that people learn by observing others. It promotes the idea that individuals are motivated to behave in a certain way based on direct or indirect social interactions [44]. Social learning theory considers how both environmental and cognitive factors interact to influence human learning and behavior. It can convincingly explain the impact of celebrities on consumption behaviors [33]. In this case, people are not just learning the importance or credibility of a product, but because someone they trust (influencer) endorses or supports the brand, they tend to do likewise and support the same brands. It is included in this study as an important foundation in understanding how social media influencers impact intention to purchase.

\subsection{Online influencers}

The background evidence to support the importance of influencers as opinion leaders is found in the social identity theory. Opinion leaders do not only act offline, but also in the online environment, and are now called digital or online influencer. A digital influencer is a person whose opinion is respected and applied in the purchase decision process [39]. He/She is a person with a certain credibility in a given area [34]. Contrary to celebrities or public figures who are well-known via traditional media, social media influencers become likeable by creating and posting content on social media [39] [31].

\subsection{Consumer Behavior}

Consumer behavior is the study of people, groups or organizations and the processes implied to select and discard products or services that meet their needs and wants [7]. The theory of planned behavior provides some conceptual frameworks for understanding the factors that affect purchase intention and assumes a causal chain that links behavioral beliefs to behavioral intentions [37], acknowledging that social networks have increasingly become a place for information sharing [7].

In previous studies certain variables were found to have an impact in consumers intentions [37]. In this research we will test originality, usefulness, quality (the antecedents), opinion leader expertise, compliance between opinion leader and promoted product, and opinion leader trustworthiness (the moderators), as factors that impact the consumers' intention to purchase.

\subsection{Influencer Trust}

Influencer potential is largely affected by trust [28]. The theory of reasoned action with the components expected to influence behavioral intention: attitude (confidence and trust) and the subjective norm (influence) [9] provides some conceptual frameworks for understanding in detail the factors (antecedents and moderators) that affect purchase intention.

Online trust is a form of relationship, and the online trust essentially includes individual perceptions of how credible the information provided by the website is and how trustworthy it is [21]. Influencer marketing's content factors, such as: perceived informativeness value (in this study represented by usefulness) and entertainment value of influencer-generated post (in this study represented by originality and quality) affect consumers' trust in the promoted content [31].

\subsection{Purchase Intention}


The purchase intention is seen as a conscious plan of consumer to purchase a product [32]. The social learning theory provides some conceptual frameworks for understanding the fundamental factors that influence the buying intention. There are four main factors that affect the consumer purchase intention [38]. First, cultural factors such as core beliefs and values and the social class in which consumers are inserted. Then, social factors such as groups, family members, friends and opinion leaders, that have a significant impact on the individual purchase decision. Third, the individual characteristics of the customer, that affect the personal motivations, perceptions and specific preferences. Then, the psychological factors that include motivation, attitudes, beliefs and individual perceptions [38].

In the following section the authors discuss the antecedents (stimuli) and the consequence (response) of the influence of opinion leadership, in order to develop the research hypotheses.

\section{Hypotheses Formulation}

The characteristics that we first focus on to formulate the hypotheses, are originality, usefulness, and quality (named the antecedents of opinion leadership) (factors pertaining to the environment), which are used as perceived characteristics that a content posted in an Instagram account should have. The opinion leadership is the central factor. Then, we focus on consumer intention to buy (named the consequence to the influence of opinion leadership) (factor related to the follower), as a desired reaction of consumer exposed to the content of the account, mediated by the influencer. We also use three other factors, perceived opinion leader expertise, perceived compliance between opinion leader and promoted product, and perceived opinion leader trustworthiness (named the moderating factors), in order to understand more complicated effects of opinion leadership on the followers' intention to buy.

Originality could be defined as the degree of newness and differentiation that some individuals achieve by performing certain actions [6]. Originality is the extent to which these actions are perceived as unusual, innovative and sophisticated [57]. Sharing posts with original content could help a fashion blog to become successful, which could generate a greater number of followers, turning the blogger into an opinion leader [35]. So, the originality of the content posted on an Instagram account can have an impact on the consumer's perception that the author is an opinion leader [6]. We propose: H1-1, "Consumer perceived content originality has an effect on perceived opinion leadership".

Usefulness is defined as the extent to which a person believes that the use of a particular system could improve the performance of their work [10]. Empirical evidence suggests that useful information is more likely to be passed on, and useful stories and marketing messages [8] are more likely to be shared. Other researchers found that perceived usefulness positively influences online buying intentions [1] [17]. This influence indicates that consumers are likely to consider buying online when they find an online environment useful for shopping. So, the degree of usefulness of the content posted on an Instagram account can have an impact on the consumer's perception that the author is an opinion leader [6]. We propose: H1-2, "Consumer perceived content usefulness has an effect on perceived opinion leadership".

Quality (of the content) has been regarded as being important in constructing a reputation in a community which [6], in turn, may lead the user to be considered as an opinion leader [26]. Sharing high quality posts (photography, writing, consistent use of logos, etc.) is a mean by which a professional and successful fashion blog can be created [35]; in this way, the blogger can become to be considered as an opinion leader in this field. Making a decision is a complicated process and evaluations take place, where consumers use their perceptions on things like quality [36]. This may change their attitude towards the promoted content. So, the quality of the content posted on an Instagram account can have an impact on the consumer perception that the author is an opinion leader [6]. We propose: H1-3, "Consumer perceived content quality has an effect on perceived opinion leadership".

Opinion leadership may influence consumer behavioral intentions. An influencer is "a new type of third-party endorser that shapes the audience through blogs, tweets and the use of other social networks" [15]. Trust in the online world is defined as one of the most influential and positive factors in the users' decisions [21]. If consumers perceived a digital influencer as a trustful source, they also will be more likely to convey the purchase intention in relation to the product being recommended [32]. Nowadays, it is common for the brands to use digital influencers to promote their products. This might be explained by some facts: 1) influencers tend to be more affordable than renowned celebrities; 2) influencers have already established themselves in certain areas, normally getting to some level of expertise, and most importantly, 3) they normally seem to be more believable in customers eyes and 
therefore they receive more trust [31]. In addition, previous studies suggest that opinion leaders exert an unequal amount of influence on the decisions of those who might follow their advice [45]. Intention to follow advice is related to the extent that individuals will follow, take into account and put into practice the suggestions of the opinion leader [42]. It is a matter of consumer buying behavior. Consumer buying behavior refers to the methods involved when individuals or groups choose, buy, utilize or dispose of products, services, concepts or experiences to suit their needs and desires [43]. The impact that opinion leadership has on the customer's intention to buy fashion products [42] has been noted. Opinion leaders tend to buy new fashion products, so they are able to advise other customers about new fashion trends that they might follow [11]. It also seems that consumers' self-esteem is increased when they buy products which have been previously recommended by a celebrity on Instagram [11]. Companies have realized the importance of purchasing intention as it will help increase the sales of products and services to maximize profits [23]. So, focusing on the Instagram context, we propose: H2, "Opinion leadership has an effect on consumer intention to purchase a recommended product".

Expertise is defined as the extent to which a communicator is perceived to be a source of valid assertions. It refers to the knowledge, experience or skills possessed by an endorser [13]. The social media influencers use the term "expertise" to indicate that they perform product-related tasks successfully [2]. Thus, if a influencer has expertized in his / her field, it will be more persuasive and subsequently will motivate the decision makers to buy the indorsed product or service [13]. So, if the opinion leader on Instagram is a source of valid assertions, he or she will tend to trust more and follow to a greater extent the ideas and behaviors suggested by the influencer [6]. We propose in our hypothesis the following interaction effect: H3-1, "The consumer perceived opinion leader expertise strengthens the influence of opinion leadership on his/her intention to purchase a recommended product".

Research has shown that endorsements are more effective when the images or messages the endorsers carry are congruent with the recommended products [46]. Early studies found that various symbolic meanings a consumer associates with a celebrity are transferred to the product being promoted through endorsement, and then from the product to the consumer through purchase and consumption. More recent studies have shown perceived congruence between celebrity image and product image as a more promising match-up factor [24]. The match-up between a product's characteristics and an endorser's image also is a critical decision in the endorsement process. The match-up has a positive correlation with consumer attitude and it will result in a significant influence on purchase intention [41]. So, a high degree of congruence between the opinion leader and the product being recommended will lead to more favorable attitudes toward the product, and hence to greater purchase intentions for the brand [6]. We propose: H3-2, "The consumer perceived compliance between opinion leader and promoted product strengthens the influence of opinion leadership on his/her intention to purchase a recommended product",

Trustworthiness refers to the target audience perception related to an endorser regarding his/her honesty, integrity and believability [13]. Furthermore, trustworthiness is how unbiased the receivers perceive the source. [47]. Most of the respondents (in a previous research) indicated that they paid their special attention to celebrities' trustworthiness when taking the purchasing decision [48]. Customers are more likely to accept the products recommended by social media influencer they feel reliable [30]. Therefore, these attributes lead to the purchase decision of the followers. So, if the opinion leader on Instagram is honest, credible and authentic, he or she will tend to trust more and follow to a greater extent the ideas and behaviors suggested by the influencer [6]. We propose in our hypothesis the following interaction effect: $\mathrm{H} 3-3$, "The consumer perceived opinion leader trustworthiness strengthens the influence of opinion leadership on his/her intention to purchase a recommended product".

All the variables as expressed by the relationships in the above formulated hypotheses are integrated in a conceptual framework.

\section{Study Methodology}

Beyond the theoretical study for this paper (literature review), which included the examination of literature (papers, books), company websites, influencers websites, survey methods, case studies, industry reports and theories, it was also important to add some quantitative evidence on the topic. The selection of a specific case is appropriate when analyzing a contemporary phenomenon, it may be used to test theory and it can be combined with quantitative evidence and a questionnaire, as in the case of this paper [50] [12].

\subsection{Purpose and objectives of research}


The aim of this paper is to explore the role that influencers on Instagram play in the behavior of the consumers, in the fashion sector in Albania. Its main objective is the identification of the impact that some antecedents (stimuli) have on the opinion leadership, as well as the impact that the latter has on the consequent (response) purchase intention of consumers, in the fashion sector in Albania.

Other objectives of this paper are:

- to identify the role that some factors (antecedents) (stimuli) play in the influence created by opinion leader.

- to identify the role that opinion leadership plays in the intentions to purchase (consequence) (response) of consumers.

- to identify the role that some other factors (moderators (with only a brief explanation for mediation)) play in the relationship of the opinion leadership and the purchase intention of consumers.

\subsection{Research subjects and population}

The data to test the proposed hypotheses were collected from a fashion related Instagram account, in which an influencer posts content related to new products in the fashion sector [6], in Albania. The selection of this specific account was not random [12]; it was based on some important characteristics: it is focused on the fashion industry, has a growing number of followers, and is accessible for our purpose (the influencer agreed to collaborate with the authors, distributing a questionnaire to the account followers). At the same time, there were a limited number of cases accessible from the authors, so this Instagram account was selected, as long as it could be categorized as an influencer account in the fashion sector in Albania. This account belonged to a nontraditional celebrity, with more than 30,000 followers, who were invited to participate in the research [50] [12].

\subsection{Sampling and data collection instruments}

To examine the proposed theoretical model (as expressed by the hypotheses formulated above), a questionnaire in Albanian language was developed. Its content validity was reviewed and revised by academics in the field. Afterwards, the accuracy of the translation from English (where the literature was found) into Albanian language was carried out. This was the tool for the data collection, motivated by the fact that prior studies investigating similar topics used the same instrument for collection of the primary data as well. The convenience sampling technique was followed, due to the fact that the study focused on the behavior of Instagram users only.
Before distributing the online questionnaire, a pilot test with a handful of randomly chosen respondents was rolled out. Yet again, the latter activity was intended to revise the accuracy of the translation and to ensure consistency throughout the whole process of filling out the form. The collected data from the pilot test were excluded from the final sample of the data. 412 participants answered the questionnaire, which included multiple-item measurement scales adapted from previous literature [58]. This helped ensure the content validity of the measures [42]. The data collection was done during the June-July 2021 time period. After filtering the data, it was realized that there were 412 valid records to be used for further analysis. The sample size of 412 is above the recommended sample size of 200 [4]. The questions asked about consumers' perceptions of the following variables: originality, usefulness, and quality of the content of the account; opinion leadership and intention to purchase, as the central elements of this research; and the perceived opinion leader expertise, perceived compliance of opinion leader with promoted product, and perceived opinion leader trustworthiness. All variables were measured by four items, which were measured on a 5-point Likert scale, ranging from 1 (strongly disagree) to 5 (strongly agree). The way variables were measured indicates that they can be called constructs.

\subsection{Used analyses}

Partial Least Square method of Structural Equation Modelling (PLS-SEM) was used to assess the variance of the internal cause of the variables (constructs) [18]. PLS-SEM was used because it is considered as a convenient method in testing direct effect and moderating effect of variables, and it informs about a particular relationship that is similar to that indicated by the traditional regression coefficients. PLS-SEM was run in SmartPLS 3.0 computer software.

Initially, the structural model was assessed with the aim to define the variables and their relationship. Then, the measurement model of the proposed conceptual framework was assessed intending the analyses of reliability, validity and discriminant validity, which could be investigated by performing a factor analysis [18]. In order to understand the statistical significance of the relationships between variables, the standardized paths were checked. The path analysis was performed using a bootstrap procedure with 5000 iterations of resampling.

\section{Study Results}


In the following paragraphs, check of the core PLSSEM's assumptions, namely collinearity, item loading, reliability, and discriminant validity among constructs, are reported.

Firstly, it is a valuable information to say that all items of the proposed constructs are included in the analysis. Based on variance inflation factor (VIF) rule of thumb, no item is dropped from the analysis, because none of them exceeded the conservative threshold of 3 (see Table 1). (Note: As Table 1. is very long, the one shown here is only a short part of it, just for demonstration purpose).

Along with VIF coefficients, in Table 1 are shown the item loadings, the Cronbach's alpha, and composite reliability values. Among 32 item loadings, 5 of them are lower than the minimum required value of 0.7 [19]. Considering the fact that those items were substantial for the respective construct, and given the relatively small difference between them and 0.7 , it was decided not to drop them from the analysis. The Cronbach's alpha coefficients ranges from 0.705 to 0.868 , while extremes values of composite reliability were 0.819 and 0.910 , the minimum and maximum respectively.

Having such figures, it can be said that the Hair et al.'s suggested bounds $(0.70-0.95)$ were not violated indicating a good construct's internal consistency reliability.

Table 1. Model measurement (not all items shown)

\begin{tabular}{|c|c|c|c|}
\hline Code & Item & Loadin & VIF \\
\hline \multirow[b]{2}{*}{ CO1 } & 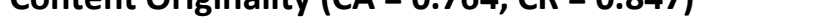 & & \\
\hline & Publications on Instagram accounts are original & 0.680 & 1.410 \\
\hline & Content Quality (CA $=0.726, C R=0.828$ ) & & \\
\hline CQ1 & The quality of publications on Instagram is very high & 0.711 & 1.362 \\
\hline
\end{tabular}

Note: $\mathrm{CA}=$ Cronbach's alpha, $\mathrm{CR}=$ Composite reliability, VIF $=$ Variance Influence Factor.

The analysis continues with the investigation of discriminant validity. By definition, discriminant validity tests whether concepts or measurements that are not supposed to be related are actually unrelated. As suggested by scholars, since PLS is a variancebased SEM, the Heterotrait-Monotrait (HTMT) criteria should be used in order to assess discriminant validity. Excluding two coefficients, the HTMT coefficients (see Table 2, below the diagonal) were below the conservative threshold of 0.85 [20]. The HTMT coefficients that pairs Intention to Purchase (IP) with Opinion Leader Compliance with Product (OLP), Opinion Leader Expertise (OLE), and
Opinion Leader Trustworthiness (OLT), were not that critical. Thus, they were considered to satisfy the assumption of discriminant analysis. Accordingly, one can say that the measured constructs fulfil the assumption of discriminant validity, meaning that the measurements are not related with each-other, indicating that they can be used in regressions as independent variables. Moreover, in Table 2, along with HTMT coefficients, the correlation coefficients between constructs are also reported. Correlation coefficients are shown above the diagonal, and HTMT (Heterotrait-Monotrait Ratio) coefficients are shown below the diagonal.

Table 2. Discriminant validity and correlations of the latent variables

\begin{tabular}{|l|llllllll|}
\hline & CO & CQ & CU & IP & OL & OLE & OLP & OLT \\
\hline CO & & 0.634 & 0.592 & 0.547 & 0.451 & 0.554 & 0.469 & 0.553 \\
CQ & 0.836 & & 0.575 & 0.561 & 0.466 & 0.596 & 0.525 & 0.652 \\
CU & 0.814 & 0.793 & & 0.619 & 0.599 & 0.579 & 0.464 & 0.555 \\
IP & 0.700 & 0.704 & 0.821 & & 0.581 & 0.729 & 0.558 & 0.726 \\
OL & 0.575 & 0.605 & 0.805 & 0.756 & & 0.464 & 0.484 & 0.465 \\
OLE & 0.734 & 0.765 & 0.793 & 0.914 & 0.607 & & 0.658 & 0.751 \\
OLP & 0.601 & 0.652 & 0.615 & 0.675 & 0.629 & 0.819 & & 0.578 \\
OLT & 0.695 & 0.794 & 0.724 & 0.862 & 0.572 & 0.911 & 0.676 & \\
\hline
\end{tabular}

Upon the confirmation of the fulfilment of PLSSEM's assumptions, the test of the structural model can be carried out. The results of the hypotheses testing are summarized in Table 3. 
The results are organized per each depended variable, which are opinion leadership and intention to purchase. Therefore, it is expected a report for only two regressions (PLS-SEM assesses several regressions, however, here are reported only the main important ones). The model explains $38.4 \%$ of the variation in opinion leadership and $65.9 \%$ of the variation in intention to purchase. According to our conceptual framework, opinion leadership is determined by content originality, content usefulness, and content quality. The empirical results have demonstrated that content usefulness $(\beta=0.469$, $t=8.816, p<0.001)$ and quality $(\beta=0.141, t=1.957$, $p=0.05)$ statistically predict opinion leadership, whereas content originality does not $(\beta=0.081, t=$ $1.248, p>0.10)$. Hence, content usefulness and content quality positively influence one's opinion leadership, as a result of the posts done by an influencer on Instagram. Based on the above findings, it can be concluded that hypotheses H1-2 and H1-3 are supported, whereas hypothesis $\mathrm{H} 1-1$ is rejected.

Table 3. Hypotheses testing

\begin{tabular}{|c|c|c|c|c|c|c|}
\hline Hypothesis & Path & $\begin{array}{c}\mathrm{R} \\
\text { square }\end{array}$ & Coefficient & T Statistics & P Values & Result \\
\hline H1-1 & $\mathrm{CO} \rightarrow \mathrm{OL}$ & & 0.081 & 1.248 & 0.212 & Rejected \\
\hline $\mathrm{H} 1-2$ & $\mathrm{CU} \rightarrow \mathrm{OL}$ & & 0.469 & 8.813 & 0.000 & Supported \\
\hline \multirow[t]{2}{*}{$\mathrm{H} 1-3$} & $\mathrm{CQ} \rightarrow \mathrm{OL}$ & & 0.141 & 1.957 & 0.050 & Supported \\
\hline & & 0.384 & & & & \\
\hline \multirow[t]{2}{*}{$\mathrm{H} 2$} & $\mathrm{OL} \rightarrow \mathrm{IP}$ & & 0.256 & 5.849 & 0.000 & Supported \\
\hline & $\mathrm{OLE} \rightarrow \mathrm{IP}$ & & 0.345 & 5.299 & 0.000 & - \\
\hline \multirow[t]{2}{*}{ H3-1 } & $\mathrm{OL} \times \mathrm{OLE} \rightarrow \mathrm{IP}$ & & -0.014 & 0.252 & 0.801 & Rejected \\
\hline & $\mathrm{OLP} \rightarrow \mathrm{IP}$ & & 0.009 & 0.197 & 0.844 & - \\
\hline \multirow[t]{2}{*}{$\mathrm{H} 3-2$} & $\mathrm{OL} \times \mathrm{OLP} \rightarrow \mathrm{IP}$ & & -0.047 & 0.979 & 0.328 & Rejected \\
\hline & $\mathrm{OLT} \rightarrow \mathrm{IP}$ & & 0.337 & 5.715 & 0.000 & - \\
\hline \multirow[t]{2}{*}{$\mathrm{H} 3-3$} & $\mathrm{OL} \times \mathrm{OLT} \rightarrow \mathrm{IP}$ & & 0.127 & 1.789 & 0.081 & Supported \\
\hline & & 0.659 & & & & \\
\hline
\end{tabular}

Note: CO - Content Originality, CU - Content Usefulness, CQ - Content Quality, OL - Opinion Leadership, OLE - Opinion Leader Expertise, OLP - Opinion Leader Compliance with Product, OLT - Opinion Leader Trustworthiness, IP - Intention to Purchase.

Hypothesis $\mathrm{H} 2$ links opinion leadership with an individual's intention to purchase. The analysis demonstrates that individuals' intention to purchase is positively affected by opinion leadership $(\beta=$ $0.256, t=5.849, p<0.001)$. Thus, hypothesis $\mathrm{H} 2$ is supported by the data.

The three last hypotheses refer to the moderating effects of the influence of opinion leadership on intention to purchase. Moderation describes a situation in which the relationship between two constructs is not constant but depends on the values of a third variable, referred to as a moderator variable. Since the objective is to identify the statistical significance of the moderator, the two-stage approach is applied to model the interaction term, as suggested by scholars [18]. Regarding the formulated hypotheses, the latter relationship is moderated by opinion leader expertise (H3-1), opinion leader compliance with product (H3-2), and opinion leader trustworthiness (H3-3). Contrary to what was proposed, evidence shows that opinion leader expertise $(\beta=-0.014, t=0.252, p>0.10)$ and opinion leader compliance with product $(\beta=-0.047, t=$ $0.979, p>0.10$ ) do not moderate the effect of opinion leadership on intention to purchase. Nevertheless, data has demonstrated that opinion leader trustworthiness statistically moderates $(\beta=0.127, t=$ $1.789, p<0.10)$ the effect of opinion leadership on intention to purchase. Thus, an individual perceived opinion leader trustworthiness strengthens the effect of opinion leadership on his/her intention to purchase a recommended product, meaning that $\mathrm{H} 3-3$ is supported.

Further to moderating effects, an investigation of the mediation effects can be performed with the aim to explore the mediation role of opinion leadership (OL) in the influences of opinion leader expertise (OLE), opinion leader compliance with product (OLP) and opinion leader trustworthiness (OLT) on intention to purchase (IP). Mediation occurs when a third mediator variable intervenes between two other related constructs [18]. It is said that mediator variable governs the nature (i.e., the underlying 
mechanism or process) of the relationship between two constructs. However, looking at the results above, perceived account characteristics (originality, usefulness, quality) may have indirect effects on consumer intention to purchase, mediated by opinion leadership. Since there is no direct link between these characteristics and consumer intention to purchase, indirect effects are expected to be equal to total effects. Therefore, these potentially mediated relationships could be analyzed, again using SmartPLS software version 3.0 [51] [6]. The results are expected to suggest that perceived usefulness and quality play a key role in developing opinion leadership on Instagram, which in turn, influences consumer behavioral intentions related to both the account and the fashion sector [6]. Nevertheless, such analysis is not performed here. It can be considered by authors as further research, firstly, to find solid theoretical foundations in support of such relationship, and then assess the effect.

\section{Conclusions}

Based on literature review and the results of the research, some important conclusions of this paper are given below:

Influencers are an important part of consumers' buying decisions. Opinion leaders are seen as a credible source of information and consumers find them trustworthy. They rely on their reviews, posted pictures and videos of promoted products/brands.

Companies should mix traditional marketing tools with social media, especially Instagram influencers, as it is highly effective to use them.

Instead of perceived originality, perceived usefulness, and perceived quality of the posts on an account are the key factors that lead a poster to be perceived as an opinion leader in Instagram.

Perceived usefulness of the content depends on the nature of that content and the benefit sought through its use or adoption.

Sharing high quality posts (photography, writing, consistent use of logos, etc.) is a mean by which a professional and successful fashion blog can be created, that is, the blogger can become to be considered as an opinion leader in this field.

As to the relationship between opinion leadership impact and the intention to purchase it can be concluded that the trustworthiness establishes a positive relationship with the intention to purchase.

The opinion leadership increases consumer intention to purchase fashion products posted on the account, which have an impact on companies' sales, due to the fact that, consumers perceive an influencer as a trustful source.
Consumers' self-esteem is increased when they buy products which have been previously recommended by a celebrity on Instagram.

Based on the hypotheses verification results, there are two unexpected results: the perceived expertise does not strengthen the influence of opinion leadership; and the perceived influencer-product congruence does not strengthen the influence of opinion leadership.

As much of the previous research support the fact that expertise and influencer-product congruence do strengthen the influence of opinion leadership on the consumer intentions, these two unexpected results may be explained by the fact that:

On one hand, given that fashion sector is a very dynamic one, where new products come out more and more often, it is probably difficult for an influencer to gain knowledge and experience about the promoted product, in a very short period of time.

On the other hand, the use of the Internet is general nowadays, and most followers may have routinized online interaction in their dynamic daily lives, so they do not want to devote enough time and thinking to detailed characteristics that describe an influencer. May be, it is enough for them that the influencer be a trustful source.

Another important explanation might be the fact that, these conclusions are based on the results of the data collected in the Albanian environment from a specific account which was not randomly selected. However, using data collected from randomly selected accounts might be the focus of another research in the future.

\section{Discussion}

In this research, a framework of the relationship between consumers' perceptions that determine the opinion leadership impact and consumers' intention to buy, was tested and validated using a sample of Instagram Albanian followers. Considering the research problem, which involved exploring the impact that influencers on Instagram have on consumer behavior, in the fashion sector in Albania, it can be affirmed that the main objective of this study was accomplished. The results of this research can be used by marketers and other industry members, who want to make effective use of social media to promote their products and increase their company sales. They can also be used by theoreticians, university researchers and other researchers that study the field. 


\section{References:}

[1] Agrebi, S., Jallais, J., Explain the intention to use smartphones for mobile shopping, J. Retail. Consum. Serv., 22, 2015, 16-23.

[2] Alba, J. W., \& Hutchinson, J. W., Dimensions of consumer expertise. Journal of Consumer Research, 13(4), 1987, 411-454.

[3] Ashforth, E., B., \& Mael, F., Social Identity Theory and the Organization. Academy of Management review, Vol. 14, No. 1, 1989, pp. 20-39.

[4] Bagozzi, R. P., \& Yi, Y., Specification, evaluation, and interpretation of structural equation models. Journal of the Academy of Marketing Science, 40(1), 2012, 8-34.

[5] Brown, D., \& Hayes, N., Influencer Marketing: Who really influences your customers?, Routledge, 2008.

[6] Casaló, L. V., Flavián, C., Ibáñez-Sánchez, S., Influencers on Instagram: Antecedents and consequences of opinion leadership. Journal of Business Research, 117, 2018, 510-519.

[7] Chaturvedi, S., \& Barbar, R., Impact of Social Media on Self-Esteem. European Scientific Journal, 2(2), 2014, 107-114.

[8] Chiu, Yi, Jin-Chern Chiou, Weilun Fang, YungJian Lin and Mingching Wu, Design, Fabrication, and Control of Components in MEMS-Based Optical Pickups, IEEE Transactions on Magnetics, 43(2), 2007, 780785.

[9] Chuchinprakarn, S., Application of the theory of reasoned action to on-line shopping. Knowledge Center Epaper Bangkok University, $1-7,2005$.

[10] Davis, F.D., Perceived usefulness, perceived ease of use, and user acceptance of information technology. MIS Q. 13 (3), 1989, 319-340.

[11] Djafarova, E., \& Rushworth, C., Exploring the credibility of online celebrities' Instagram profiles in influencing the purchase decisions of young female users. Computers in Human Behavior, 68, 2017, 1-7.

[12] Eisenhardt, K. M., Building theories from case study research. The Academy of Management Review, 14(4), 1989, 532-550.

[13] Erdogan, B., Celebrity Endorsement: A Literature Review. Journal of Marketing Management, 15(4), 1999, 291-314.

[14] Erdogmus, E., \& Çiçek, M., The Impact of Social Media Marketing on Brand Loyalty. Procedia - Social and Behavioral Sciences, 58, 2012, 1353-1360.

[15] Freberg, K., et al., Who are the social media influencers? A study of public perceptions of personality. Public Relations Review, 2010.
[16] Goh, K.Y., Heng, C.S., \& Lin, Z., Social media brand community and consumer behavior: Quantifying the relative impact of user- and marketer-generated content. Information Systems Research, 24(1), 2013, 88-107.

[17] Grob, M., Exploring the acceptance of technology for mobile shopping: an empirical investigation among smartphone users. Int. Rev. Retail Distrib. Consum. Res 25 (3), 2015, 215235

[18] Hair, J. F., Hult, G. T. M., Ringle, C. M., \& Sarstedt, M., A Primer on Partial Least Squares Structural Equation Modeling (2nd ed.). Los Angelos: Sage, 2017.

[19] Hair, J. F., Risher, J. J., Sarstedt, M., \& Ringle, C. M., When to use and how to report the results of PLS-SEM. European Business Review, 31(1), 2019, 2-24.

[20] Henseler, J., Ringle, C. M., \& Sarstedt, M., A new criterion for assessing discriminant validity in variance-based structural equation modeling. Journal of the Academy of Marketing Science, 43(1), 2015, 115-135.

[21] Ho, H.Y., \& Chien, P.H.C., Influence of message trust in online word-of-mouth on consumer behavior - by The example of food blog. International Conference on Electronics and Information Engineering, 2010, 395-399.

[22] Hoonsopon, D., \& Puriwat, W., The effect of reference groups on purchase intention: Evidence in distinct types of shoppers and product involvement. Australasian Marketing Journal, 24(2), 2016, 157-164.

[23] Hosein, N.Z., Measuring Purchase Intention of Visitors to The Auto Show. Journal of Management and Marketing Research. 2012, 117.

[24] Kamins, M. A., \& Gupta, K., Congruence between spokesperson and product type: A matchup hypothesis perspective. Psychology \& Marketing, 11, 1994, 569-586.

[25] Kietzman, J. H., Hermkens, K., McCarthy, I. P., \& Silvestre, B. S., Social media? Get serious! Understanding the functional building blocks of social media. Business Horizons, 54(3), 2011, $241-251$.

[26] Leal, G. P. A., Hor-Meyll, L. F., \& de Paula Pessôa, L. A. G., Influence of virtual communities in purchasing decisions: The participants' perspective. Journal of Business Research, 67(5), 2014, 882-890.

[27] Lee, J., E., \& Watkins, B., YouTube vloggers' influence on consumer luxury brand perceptions and intentions. Journal of Business Research, 69 (12), 2016, 5753--60. 
[28] Lindh, C., \& Lisichkova, N., Rationality versus emotionality among online shoppers: The mediating role of experts as enhancing influencer effect on purchasing intent. Journal of Customer Behaviour, 16(4), 2017, 333-351.

[29] Lipsman, A., Mudd, G., Rich, M., \& Bruich, S., The power of "like": How brands reach (and influence) fans through social-media marketing. Journal of Advertising Research, 52, 2012, 4052.

[30] Liu, S., Jiang, C., Lin, Z., Ding, Y., Duan, R., \& $\mathrm{Xu}, \mathrm{Z}$., Identifying effective influencers based on trust for electronic word-of-mouth marketing: A domain-aware approach. Information Sciences, 306, 2015, 34-52.

[31] Lou, C., \& Yuan, S., Influencer Marketing: How Message Value and Credibility Affect Consumer Trust of Branded Content on social media. Journal of Interactive Advertising, Volume 19, Issue 1. 2019, 58-73.

[32] Lu, L.C. Chang, W.P., \& Chang, H.H., Consumer attitudes toward blogger's sponsored recommendations and purchase intention: The effect of sponsorship type, product type, and brand awareness. Computers in Human Behavior, 34, 2014, 258-266.

[33] Makgosa, R., The influence of vicarious role models on purchase intentions of Botswana teenagers, Young Consumers, vol. 11, no. 4, 2010, pp. 307-319.

[34] Mangold, W. G., \& Faulds, D. J., Social media: The new hybrid element of the promotion mix. Business Horizons, 52(4), 2009, 357-365.

[35] Mendola, M. A., Blogging in the fashion industry: A descriptive study of the use of the two-step flow communications theory by professional and citizen bloggers to become opinion leaders. Senior project. San Luis Obispo: The Faculty of the Journalism Department, California Polytechnic State University, 2014.

[36] Mirabi, V., R., \& Goohari, B., Investigating the effectiveness of the marketing mix factors on sale growth (Case study: Trading companies of Ilam). Visi Jurnal Akademik, 6: 2015, 83-88.

[37] Montano, D. E., \& Kasprzyk, D., Theory of reasoned action, theory of planned behavior, and the integrated behavioral model. Health behavior: Theory, research and practice, 70(4), 2015, 231.

[38] Oke, A., Kamolshotiros, P., Yewande Popoola, O., Akintunde Ajagbe, M., \& Olujobi, J. O., Consumer behavior towards decision making and loyalty to particular brands. International
Review of Management and Marketing - Asia International Conference, 6(S4), 2016, 43-52.

[39] Pereira da Costa, I., \& Alturas, B., Portuguese digital opinion leaders and its impact, in the promotion of products, services and events in social networks, 13th Iberian Conference on Information Systems and Technologies (CISTI), 2018, pp. 1-7,

[40] Phua, J., Jin, S. V., \& Kim, J., Gratifications of using Facebook, Twitter, Instagram, or Snapchat to follow brands: The moderating effect of social comparison, trust, tie strength, and network homophily on brand identification, brand engagement, brand commitment, and membership intention. Telematics and Informatics, 34(1), 2017, 412-424.

[41] Pradhan, D., Duraipandian, I., and Sethi, D., Celebrity endorsement: How celebrity- branduser personality congruence affects brand attitude and purchase intention, Journal of Marketing Communications, vol. 22, no. 5, 2016, pp. 456-473.

[42] Rahman, S. U., Saleem, S., Akhtar, S., Ali, T., $\&$ Khan, M. A., Consumers' adoption of apparel fashion: The role of innovativeness, involvement, and social values. International Journal of Marketing Studies, 6(3), 2014, 4964.

[43] Solomon, M., Consumer Behavior, Prentice Hal, New Jersey, 1995.

[44] Subramanian, S. and Subramanian, A., Reference Group Influence on Innovation Adoption Behaviour: Incorporating Comparative and Normative Referents, European Advances in Consumer Research, vol. 2, 1995, pp. 14-18.

[45] Thakur, R., Angriawan, A., \& Summey, J. H., Technological opinion leadership: The role of personal innovativeness, gadget love, and technological innovativeness. Journal of Business Research, 69(8), 2016, 2764-2773.

[46] Till, B. D., Stanley, S. M., \& Priluck, R., Classical conditioning and celebrity endorsers: An examination of belongingness and resistance to extinction. Psychology \& Marketing, 25, 2008, 179-196.

[47] Van der Waldt, D. L. R., Van Loggerenberg, M., \& Wehmeyer, L., Celebrity endorsements versus created spokespersons in advertising: A survey among students. South African Journal of Economic and Management Sciences, 12(1), 2009, 100-114.

[48] Weerasiri, S., \& Wanninayake, W., Impact of the celebrity endorsements on consumer buytng 
behaviors. Sri Lanka Journal of Social Sciences, 1(1), 2009, 103-116.

[49] Xie, K. \& Lee,Y. J., Social media and brand purchase: Quantifying the effects of exposures to earned and owned social media activities in a two-stage decision making model. Journal of Management Information Systems, 32(2), 2015, 204-238.

[50] Yin, R., Case study research: Design and methods (2nd ed.). Beverly Hills, CA: Sage Publishing, 1994.

[51] Ringle, C. M., Wende, S., \& Becker, J. M., SmartPLS 3. Boenningstedt:SmartPLS GmbH., 2015.

[52] Santiago, K., J., Magueta, D., \& Dias, C., Consumer attitudes towards fashion influencers on Instagram: impact of perceptions and online trust on purchase intention.Issues in Information Systems, Volume 21, Issue 1, 2020, 105-117.

[53] Młodkowska, B., Infl uencers on Instagram and YouTube and Their Impact on Consumer Behaviour. Journal of Marketing and Consumer Behaviour in Emerging Markets, 1(9), 2019.

[54] Teng, S., \& Khong, W., K., Examining the antecedents of persuasive eWOM messages in social media. Online Information Review, Vol. 38 Iss 6, 2014, 746 - 768.

[55] Stratigopoulou, E., Ntalianis, K., Kikili, V., \& Ntalianis, F., Risks Inherent in Inaccurate or Inadvertent use of Social Networks in Greece. International journal of education and information technologies, Volume 14, 2020, 108-114.

[56] De Veirman, M., Cauberghe, V., \& Hudders, L. (2017). Marketing through Instagram influencers: The impact of number of followers and product divergence on brand attitude. International Journal of Advertising, 36(5), 798-828.

[57] Derbaix, C., \& Vanhamme, J. (2003). Inducing word-of-mouth by eliciting surprise-A pilot investigation. Journal of Economic Psychology, 24(1), 99-116.

[58] Gentina, E., Butori, R., \& Heath, T. B. (2014). Unique but integrated: The role of individuation and assimilation processes in teen opinion leadership. Journal of Business Research, 67(2), 83-91.

\section{Contribution Of Individual Authors To The Creation Of A Scientific Article (Ghostwriting Policy)}

\author{
Author Contributions: \\ Kreshnik Bello carried out the Conceptualization and \\ was responsible for the Methodology development, \\ Finding of resources, Formal analysis and Writing of \\ the original draft. \\ Hysen Muceku was responsible for the Methodology \\ development, Validation of results and Development \\ of conclusions. \\ Margarita Ndoka was responsible for the \\ Investigation process, Methodology development, \\ Formal analysis and the Validation of results. \\ Follow: www.wseas.org/multimedia/contributor- \\ role-instruction.pdf
}

\section{Sources of funding for research presented in a scientific article or scientific article itself}

The study was funded by the authors of the paper.

\section{Creative Commons Attribution License $\quad 4.0 \quad$ (Attribution $\quad 4.0$ International, CC BY 4.0)}

This article is published under the terms of the Creative Commons Attribution License 4.0 https://creativecommons.org/licenses/by/4.0/deed.en $\underline{\mathrm{US}}$ 